\section{Heartburn of Pregnancy}

"A warm discomfort situated in the epigastrium or retrosternal region, usually radiating up to the throat or more rarely across the chest, and ... usually associated with intake of food or change in posture." This is a common symptom and one that most people experience from time to time and come to recognize as a benign nuisance. In pregnancy it is particularly common and troublesome, occurring in two thirds of Caucasian woman in Sheffield and Liverpool and in a similar proportion of Negro women in Chicago. ${ }^{2}$ It occurs in particular during the second and third trimesters of pregnancy. A previous suggestion ${ }^{3}$ that it is relieved during the last four weeks of pregnancy, when the fetal head descends into the pelvis, has not been substantiated. ${ }^{2}$ This suggests that raised intra-abdominal pressure is not the main cause of heartburn, and recent research indicates that more subtle mechanisms are at play.

The lower oesophageal sphincter maintains the barrier between the stomach and the oesophagus. The pressure that it exerts can be measured by traversing this area with an open-ended tube filled with fluid which is constantly infused during the measurement. By this procedure various artefacts have been eliminated, and a true and reproducible recording can be obtained. By this technique it has been shown that, so long as this sphincter is working and gastric contents do not enter the lower oesophagus, patients do not have symptoms of reflux oesophagitis, even if they have a hiatus hernia. The functioning of this sphincter appears to be of more importance than whether the stomach is above or below the diaphragm. ${ }^{45}$ The integrity of the sphincter is reduced by smoking 6 and a fall in the blood level of gastrin. ${ }^{7}$

If gastrin can do this why not other hormones? In relation to heartburn of pregnancy this would seem to be a useful line of study, for the hormonal changes that occur during pregnancy are known to affect the functioning of smooth muscle in other parts of the body, such as the ureters. In a recent study the pyloric sphincter has been shown to be incompetent in patients with pregnancy heartburn, which would be in keeping with the idea that hormonal factors may be affecting the functioning of smooth muscle in various organs.

Once the lower oesophageal sphincter is incompetent, gastric contents enter the lower oesophagus. Acid in this area produces the pain, and heartburn is also caused by reflux of bile through pyloric and lower oesophageal sphincters. ${ }^{89}$ Perhaps reflux of bile into the oesophagus is more important in the pathogenesis of heartburn than the reflux of gastric acid. ${ }^{10}$

The histological consequences of gastro-oesophageal reflux have been accurately assessed in a careful study. Suction biopsy specimens were obtained from patients with and without reflux.11 The earliest changes in the lower oesophageal mucosa were basal cell hyperplasia of the squamous epithelium and location of the papillae close to the epithelial surfaces. These changes are the ones that would be expected if there was an increased turnover of epithelial cells in response to the oesophageal insult. Eightyfive per cent. of subjects with heartburn have been shown to have these early histological changes in the lower oesophageal mucosa, whereas these changes were not present in $90 \%$ of normal controls. ${ }^{11}$ An interesting point from this study was that seven of the patients with heartburn who had histo- logical changes did not have demonstrable gastro-oesophageal reflux. It is suggested that in these patients reflux was intermittent, which is why it was not detected at the time of the investigation. There were also nine patients in this study who had reflux but who had no symptoms. About half of these patients had histological changes. Thus there are some patients who have asymptomatic reflux associated with histological changes in the lower oesophageal muscosa.

Most patients who have occasional mild heartburn learn to avoid conditions that provoke the symptoms. Frequent small meals, milk, alkali, and avoidance of bending or lying flat frequently improve the symptoms. Obese patients should be advised to lose weight, and it is surprising how often the symptoms then improve. There is recent evidence that metoclopropamide $10 \mathrm{mg}$ three times a day is more effective than a placebo in relieving heartburn, ${ }^{12}$ and it can be tried in resistant cases. Unless the symptoms are very severe it would not seem justifiable to use it during pregnancy. Antacid preparations that float on the surface of the gastric contents and are said to prevent reflux by blockage of the cardiac opening have not been proved to be better than simple antacids, but they are worth a trial in resistant cases.

\footnotetext{
1 Tuttle, S. G., Rufin, F., and Bettarello, A., Annals of Internal Medicine, 1961, 55, 292.

2 Atlay, R. D., Gillison, E. W., and Horton, A. L., Fournal of Obstetrics and Gynaecology of the British Commonwealth, 1973, 80, 63.

3 Rodway, H. E., and Shelley, U., fournal of Obstetrics and Gynaecology, of the British Commonwealth, 1935, 42, 107.

+ Winans, C. S., and Harris, L. D., Gastroenterology, 1967, 52, 773.

5 Cohen, S., and Harris, L. D., New England Fournal of Medicine, 1971, 284, 1053 .

6 Stanciu, C., and Bennett, J. R, Gut, 1972, 13, 318.

7 Castell, D. O., and Harris, L. D., New England Fournal of Medicine, $1970,282,886$.

8 Bernstein, L. M., and Baker, L. A. Gastroenterology, 1958, 34, 760.

Gillison, E. W., Capper, W. M., Airth, G. R., Gibson, M. J., and Bradford, I, Gut, 1969, 10, 609.

10 Gillison, E. W., Nyhus, L. M., and Duthie, H. L. British fournal of Surgery, $1971,58,864$.

1 Ismail-Beigi, F., Horton, P. F., and Pope, C. E., Gastroenterology, 1970 , 58, 163.

12 Johnson, A. G., British Medical fournal, 1971, 2, 25.
}

\section{Malignancy of Bronchial Adenoma}

The bronchial adenoma is a white, somewhat circumscribed tumour arising from the wall of a bronchus. It is usually central, deriving from one of the major bronchi, and it leads to collapse of the distal lung, with inevitable superadded infection. The main symptoms are cough, haemoptysis, wheezing, and fever. The rarer peripheral tumour is usually discovered during a routine radiological examination of the chest. The mass that projects into the bronchial lumen is only a small part of a much more extensive tumour that spreads outside the confines of the bronchus. Bronchial adenomata form about $1 \%$ of all primary lung tumours and are traditionally described as slow-growing. But their malignant potentiality is well recognized, for they infiltrate locally and may metastasize to distant organs. ${ }^{1-5}$

Histologically three main types are recognized. The commonest is the carcinoid tumour, which is similar in structure to the better known argentaffinoma of the gastrointestinal tract. It arises from the cells of Kulschitzky of the bronchial mucosa and from neurosecretory cells of mucous glands. It has recently been noted that similar neurosecretory granules may be found in the oat-cell 